Bài báo khoa học

\title{
Đánh giá tác động của biến đổi khí hậu đến tiềm năng khai thác khoáng sản tỉnh Bình Phước
}

\section{Lê Hoài Nam ${ }^{*}$, Hồ Công Toàn², Phạm Thanh Long²}

${ }^{1}$ Trung tâm Quan trắc Môi trường miền Nam; lhnammt@gmail.com

${ }^{2}$ Phân Viện Khoa học Khí tượng Thủy văn và Biến đổi khí hậu; hocongtoanhdh@gmail.com; longphamsihymete@gmail.com

*Tác giả liên hệ: lhnammt@gmail.com; Tel.: +84-913145914

Ban Biên tập nhận bài: 16/3/2021; Ngày phản biện xong: 8/5/2021; Ngày đăng bài: $25 / 6 / 2021$

Tóm tắt: Nghiên cứu đưa ra kết quả phân tích, đánh giá tác động của biến đổi khí hậu $(\mathrm{BĐKH})$ đến tiềm năng khai thác khoáng sản ở tỉnh Bình Phước. Để thực hiện đánh giá nghiên cứu đã kế thừa kết quả xây dựng kịch bản nhiệt độ, lượng mưa, hạn hán và ngập theo kịch bản $\mathrm{B} Đ K H$ và nước biển dâng $(\mathrm{NBD})$ năm 2016 của Bộ Tài nguyên và Môi trường và bộ chỉ số đánh giá được xây dựng theo hướng dẫn của Ban Liên Chính phủ về Biến đổi khí hậu (IPCC) năm 2007. Trên cơ sở đó, kết quả về mức độ tác động và ảnh hưởng của $\mathrm{B} Đ K H$ đến khu vực khai thác khoáng sản ở tỉnh Bình Phước được đánh giá đến từng huyện và khu vực, cụ thể: các khu vực khai thác khoáng sản ở thành phố Đồng Xoài (TP. Đồng Xoài) chịu mức độ tác động thấp nhất từ $0,36-0,38$; huyện Bù Gia Mập có mức tác động do $\mathrm{B} Đ K H$ đến khu vực khai thác khoáng sản ở mức cao, với chỉ số tác động khoảng 0,6 . Những địa phương còn lại của tỉnh Bình Phước có tiềm năng khai thác khoáng sản bị tác động vừa với chỉ số tác động từ $0,43-0,53$ dưới ảnh hưởng của $\mathrm{BĐKH.} \mathrm{Tuy} \mathrm{bài} \mathrm{báo} \mathrm{mới} \mathrm{chỉ} \mathrm{đưa} \mathrm{ra} \mathrm{mức}$ độ tác động của $\mathrm{BĐKH,} \mathrm{chưa} \mathrm{đề} \mathrm{cập} \mathrm{đến} \mathrm{những} \mathrm{chỉ} \mathrm{số} \mathrm{khác} \mathrm{nhưng} \mathrm{kết} \mathrm{quả} \mathrm{nghiên} \mathrm{cứu} \mathrm{đã}$ góp phần cung cấp thông tin cho tỉnh Bình Phước, phục vụ quy hoạch những khu vực khai thác khoảng sán trước bối cảnh BĐKH.

Từ khóa: Mức độ tác động; Biến đổi khí hậu; Khoáng sản.

\section{Mở đầu}

Đánh giá tác động do $\mathrm{BĐKH} \mathrm{là} \mathrm{nghiên} \mathrm{cứu} \mathrm{xác} \mathrm{định} \mathrm{các} \mathrm{ảnh} \mathrm{hưởng} \mathrm{của} \mathrm{BĐKH} \mathrm{lên} \mathrm{môi}$ trường và các hoạt động kinh tế xã hội của địa phương. Ngoài ảnh hưởng bất lợi còn có thể mang lại những ảnh hưởng có lợi. Đánh giá tác động của $\mathrm{BĐKH} \mathrm{cũng} \mathrm{bao} \mathrm{gồm} \mathrm{việc} \mathrm{xác} \mathrm{định}$ và đánh giá các giải pháp thích ứng với $\mathrm{BĐKH} \mathrm{[1].} \mathrm{Hiện} \mathrm{nay} \mathrm{có} \mathrm{nhiều} \mathrm{cách} \mathrm{tiếp} \mathrm{cận} \mathrm{trong}$ đánh giá tác động của BĐKH. Theo IPCC, có 3 cách: Tiếp cận tác động (impact-approach), tiếp cận tương tác (interaction-approach) và tiếp cận tổng hợp (integrated-approach). Mỗi cách tiếp cận có những điểm mạnh và hạn chế riêng, theo đó, tùy thuộc vào nhiều yếu tố khác nhau (yêu cầu đánh giá, phạm vi, khung thời gian và nguồn lực...) để lựa chọn [1-2].

Đánh giá tác động của $\mathrm{BĐKH} \mathrm{bao} \mathrm{gồm} \mathrm{các} \mathrm{phương} \mathrm{pháp} \mathrm{định} \mathrm{tính} \mathrm{và} \mathrm{định} \mathrm{lượng,} \mathrm{chia}$ thành các nhóm chính: (i) các phương pháp thực nghiệm: Trong đánh giá tác động của $\mathrm{BĐKH}$, phương pháp này được dùng để xác định các yếu tố khí hậu và môi trường (nhiệt độ, lượng mưa, ngập, xâm nhập mặn, ...) đến đối tượng nghiên cứu (năng suất cây trồng, nguy cơ dịch bênh, ...); (ii) phương pháp ngoại suy số liệu lịch sử: các mô hình toán được sử dụng để dự đoán những tác động trong tương lai bằng cách ngoại suy các số liệu trong quá khứ; 
(iii) các phương pháp ngoại suy, nghiên cứu sử dụng các trường hợp tương tự: sử dụng số liệu của các trường hợp tương tự ở một khu vực khác để đánh giá tác động của $\mathrm{B} Đ K H$ lên đối tượng đang xem xét. Các loại nghiên cứu tương tự được dùng là: sự kiện lịch sử tương tự, xu hướng lịch sử tương tự, khu vực khí hậu hiện tại và tương lai tương tự; (iv) phương pháp chuyên gia: phương pháp này tập hợp các ý kiến và đánh giá của các chuyên gia (từ các tài liệu, các báo cáo đánh giá hoặc các cuộc họp chuyên gia, hội thảo, ...) [1]. Bên cạnh đó, đánh giá tác động của $\mathrm{B} Đ K H$ cũng có thể thực hiện theo phương pháp có sự tham gia của cộng đồng và các bên liên quan ở địa phương [1]. Thời gian đầu, xu hướng nghiên cứu tác động của $\mathrm{B} Đ K H$ tập trung vào các tác động đơn thuần đến những biểu hiện của $\mathrm{BĐKH}$. Xây dựng kịch bản $\mathrm{BĐKH}$ và NBD cho Việt Nam theo hướng dẫn của IPCC [3-4]; Đánh giá hiện trạng ngập lụt và xác định kịch bản $\mathrm{BĐKH}$ và $\mathrm{NBD}$ cho $\mathrm{TP}$. Hồ Chí Minh [5] hay xây dựng kịch bản $\mathrm{BĐKH} \mathrm{và} \mathrm{dự} \mathrm{báo} \mathrm{xâm} \mathrm{nhập} \mathrm{mặn} \mathrm{theo} \mathrm{kịch} \mathrm{bản} \mathrm{B} Đ K H$ cho khu vực Đồng bằng sông Cửu Long [6]. Năm 2020, nghiên cứu [7] đã tiến hành xây dựng bản đồ phân bố cấp độ tác động của $\mathrm{B} Đ K H$ đến quy hoạch, thăm dò, khai thác, chế biến và sử dụng các khoáng sản chủ yếu ở Việt Nam. Cùng năm, [8] đã thực hiện đánh giá tác động của nước biển dâng do $\mathrm{BĐKH}$ đến vùng nuôi trồng thủy sản khu vực ven biển Bắc Bộ và Bắc Trung Bộ. [9] đã đánh giá tác động của $\mathrm{B} Đ K H$ đến ngập lụt tại $\mathrm{TP}$. Hồ Chí Minh và đề xuất giải pháp thích ứng với $\mathrm{B} Đ K H$. Nghiên cứu [10] đã đánh giá tác động của $\mathrm{BĐKH}$ đến tự nhiên, con người và kinh tế-xã hội thành phố Hồ Chí Minh. Bên cạnh đó, Bộ Tài nguyên và Môi trường đã chù trì xây dựng Thông báo quốc gia lần thứ hai [11], lần thứ ba [12] cho Công uốc khung của Liên Hợp Quốc về $\mathrm{B} Đ K H$ nhằm cung cấp thông tin về kiếm kế quốc gia khí nhà kính (KNK), phân tích, đánh giá tác động của $\mathrm{BĐKH}$, giảm nhẹ phát thải $\mathrm{KNK}$ trong các ngành, lĩnh vực kinh tế-xã hội chủ yếu ở Việt Nam.

Trước các sức ép về tốc độ phát triển kinh tế-xã hội trên địa bàn tỉnh Bình Phước, sự gia tăng các hoạt động các hoạt động khai thác khoáng sản quá mức mà không quan tâm đến những biến đổi của khí hậu sẽ ảnh hưởng rất lớn đến những quy hoạch tương lai của Tỉnh, đồng thời, khai thác khoáng sản không quan tấm đến các biện pháp phòng chống nhiệt độ tăng, lượng mưa thay đổi, mưa cực đoan hay ngập sẽ làm giảm năng suất và gây thoái hóa đất ở những vùng khai thác khoáng sản. Để nghiên cứu đánh giá tác động của $\mathrm{BĐKH} \mathrm{đến}$ tiềm năng khái thác khoáng sản, nhóm tác giả đã sử dụng phương pháp bộ chỉ số đánh giá dựa trên những kết quả kịch bản của mô hình khí hậu và mô hình ngập. Với mục tiêu đánh giác tác động của $\mathrm{BĐKH} \mathrm{đến} \mathrm{tiềm} \mathrm{năng} \mathrm{khai} \mathrm{thác,} \mathrm{vùng} \mathrm{khai} \mathrm{thác} \mathrm{khoảng} \mathrm{sản} \mathrm{theo} \mathrm{các} \mathrm{cấp}$ thang đo trong bộ chỉ số cho tỉnh Bình Phước.

\section{Phương pháp nghiên cứu}

\subsection{Giới thiệu khu vục nghiên cứu}

Nghiên cứu được thực hiện trên khu vực tỉnh Bình Phước, là một tỉnh thuộc miền Đông Nam Bộ, có đường biên giới tiếp giáp với Campuchia dài 260,433km (Hình 1). Khu vực nghiên cứu có địa bàn trung chuyển giữa Nam Tây Nguyên và miền Đông Nam Bộ, nên tỉnh có địa hình rất đa dạng, gồm cả địa hình cao nguyên, đồi núi và đồng bằng. Nằm trong vùng kinh tế trọng điểm phía Nam, có vị trí không xa Thành phố Hồ Chí Minh - trung tâm kinh tể lớn nhất của cả nước-lại có cửa khẩu thông thương với Campuchia, Bình Phước có rất nhiều cơ hội để phát triển thương mại, du lịch và xuất khẩu, ... Tài nguyên khoáng sản tỉnh Bình Phước không đa dạng về chủng loại nhưng một số có trữ lượng khá lớn, có giá trị công nghiệp. Theo kết quả điều tra của Liên đoàn Địa chất Bản đồ Miền Nam, tỉnh hiện có 91 mỏ, điểm quặng, điểm khoáng hóa và phân bố rải rác, chủ yếu ở vùng phía Tây và một ít ở trung tâm với các loại khoáng sản như: than bùn, đá xây dựng, cát, cuội sỏi, sét gạch ngói, laterit, sỏi đỏ. Theo những kết quả xây dựng kịch bản $\mathrm{BĐKH,} \mathrm{đến} \mathrm{giữa} \mathrm{thế} \mathrm{kỷ} \mathrm{nhiệt} \mathrm{độ} \mathrm{trung} \mathrm{bình}$ tỉnh Bình Phước tăng $1,40^{\circ} \mathrm{C}$, lượng mưa năm có mức biến đổi từ $9,2-9,9 \%$. Vào cuối thế kỷ, mức tăng nhiệt độ khoảng $1,9^{\circ} \mathrm{C}$. Đối với lượng mưa mức biển đổi khoảng $14,5-16,6 \%$ theo 
kịch bản phát thải trung bình (RCP4.5) [3]. Với những biến đổi về nhiệt độ và lượng mưa như vậy tạo nên sự khắc nghiệt có khả năng thúc đẩy các quá trình hạn hán, hoang mạc hóa đất, nguy cơ ngập, lũ cũng gia tăng và tác động bởi các hiện tượng cực đoan như mưa cực đoan, dông, sét cũng tăng lên đáng kể [3].

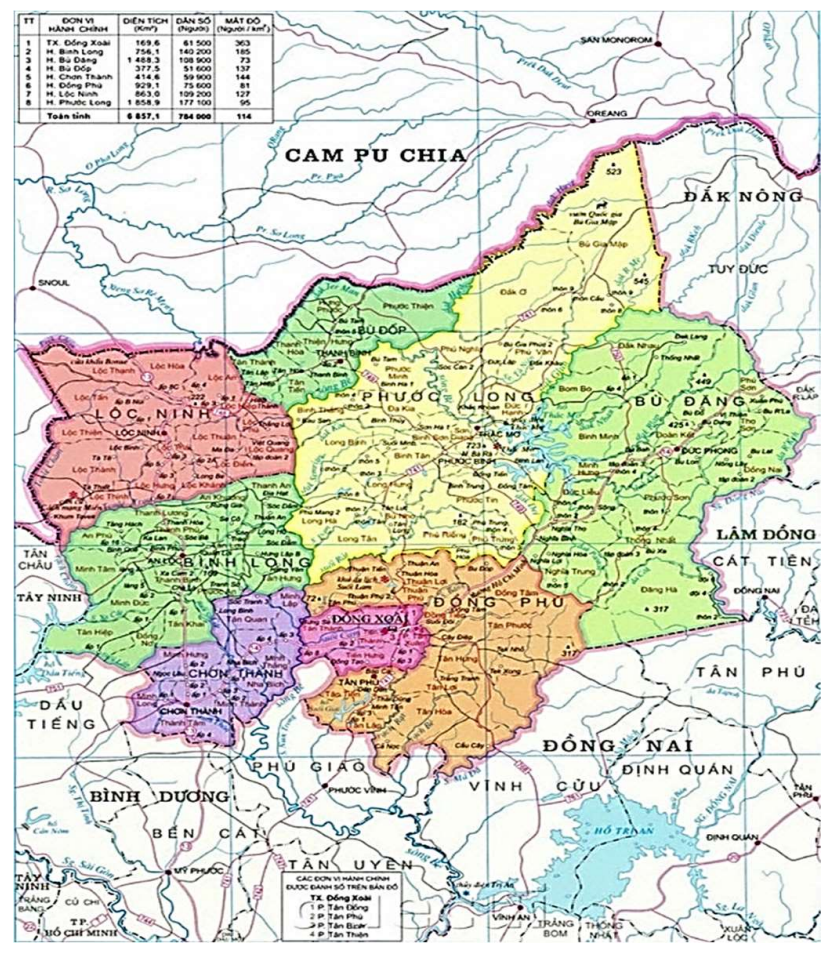

Hình 1. Bản đồ hành chính tỉnh Bình Phước [13].

\subsection{Phuơng pháp đánh giá tác động của BĐKH bằng chi số (kết hơp GIS)}

Chỉ số những tác động của BĐKH được xác lập trong mối quan hệ của 03 yếu tố (Hình 12): mức độ phơi nhiễm $(\mathrm{E})$, mức độ nhạy cảm $(\mathrm{S})[1,14]$. Các thuật ngữ này có thể thay đổi trong các nghiên cứu khác nhau.

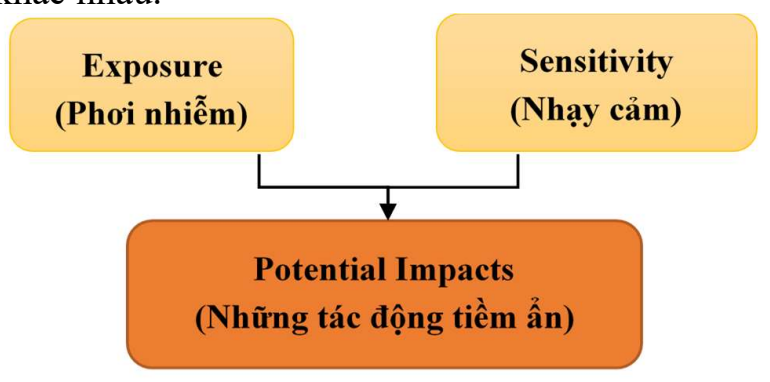

Hình 2. Mô hình ý niệm đánh giá tính DBTT do BĐKH [1].

Áp dụng phương pháp chỉ số để đánh giá tác động tiềm ẩn và tính dễ bị tổn thương (DBTT) đối với biến đổi khí hậu theo quy trình như sau [1-2]:

Bước 1: Xác định bộ chỉ thị (BCT)

$\mathrm{BCT}$ và trọng số tương ứng phục vụ đánh giá tác động của $\mathrm{BĐKH} \mathrm{(Bảng} 2$ và 3 ) bao gồm các chỉ thị thể hiện khả năng phơi nhiễm $(\mathrm{E})$, tính nhạy cảm $(\mathrm{S})$ (từ đó đánh giá được tác động I). Phương pháp tổng quan tài liệu và tham vấn chuyên gia cũng đồng thời được sử dụng ở nội dung này.

Bước 2: Chuẩn hóa các số liệu thực (chỉ thị) theo thang điểm 0-1 
Các chỉ thị có đơn vị và tỷ lệ khác nhau, vì thế cần chuẩn bằng cách đồng nhất giá trị từ 0-1 (bảng 1).

- Đối với các chỉ thị tỉ lệ (\%): nếu tỉ lệ được xét trong cùng một hệ thống (toàn vùng nghiên cứu), chỉ thị được chuẩn hoá bằng cách giữ nguyên giá trị và bỏ đơn vị \%.

- Đối với hầu hết các chỉ thị $\mathrm{E}$ (như nhiệt độ, lượng mưa, bão), $\mathrm{S}$ và $\mathrm{AC}$ : chuẩn hóa theo công thức sau:

+ Quan hệ thuận với cấu phần đang xét:

$$
\text { Chî số }=\frac{\text { (Giá trị thực }- \text { Giá trị nhỏ nhất })}{\text { (Giá trị lớn nhất }- \text { Giá trị nhỏ nhất })}
$$

+ Quan hệ nghịch với cấu phần đang xét:

Bước 3: Tính toán chỉ số tổng hợp

$$
\text { Chỉ số }=\frac{\text { (Giá trị lớn nhất }- \text { Giá trị thực) }}{\text { (Giá trị lớn nhất }- \text { Giá trị nhỏ nhất) }}
$$

Chỉ số tổng hợp của từng cấu phần $(\mathrm{E}, \mathrm{S})$ được tính toán dựa trên giá trị chuẩn hoá của chỉ thị $i$ và trọng số ưu tiên wi theo các công thức dưới đây. Chỉ số I là hàm số của nhóm chỉ số $\mathrm{E}$ và $\mathrm{S}$.

$$
E=\sum_{i=1}^{n} E_{i} * \mathrm{WE}_{i}(3) \quad S=\sum_{i=1}^{n} S_{i} * W S_{i} \text { (4) } \quad \mathrm{I}=\mathrm{E} * \mathrm{~S}(5)
$$

Trong đó $\mathrm{I}$ là tác động của thiên tai; $\mathrm{E}$ là nguy cơ hứng chịu thiên tai; $\mathrm{S}$ là các tổn thất đối với thiên tai (mức độ nhạy cảm với nguy cơ thiên tai); $\mathrm{E}_{\mathrm{i}}, \mathrm{S}_{\mathrm{i}}$ lần lượt là giá trị chuẩn hoá của chỉ thị thứ i trong cấu phần $\mathrm{E}, \mathrm{S}$; $\mathrm{w}_{\mathrm{Ei}}$, $\mathrm{w}_{\mathrm{Si}}$ lần lượt là trọng số ưu tiên của chỉ thị thứ $\mathrm{i}$ trong cấu phần $\mathrm{E}, \mathrm{S} ; \mathrm{n}$ làsố lượng các chỉ thị thành phần (của mỗi cấu phần $\mathrm{E}, \mathrm{S}, \mathrm{AC}$ ).

Bước 4: Thành lập bộ chỉ số và đánh giá

Bảng 1. Thang chỉ số đánh giá $\mathrm{E}, \mathrm{S}$ và $\mathrm{I}[2]$.

\begin{tabular}{|c|c|c|c|}
\hline Hiện tưọ̣ng (1) & Chỉ thị (2) & Ký hiệu & Quan hệ \\
\hline Nhiệt độ & $\begin{array}{l}\text { Mức độ gia tăng nhiệt độ tối cao so với giai } \\
\text { đoạn } 1986-2005\left({ }^{\circ} \mathrm{C}\right)\end{array}$ & E.1.1 & + \\
\hline Lượng mưa & $\begin{array}{l}\text { Mức độ gia tăng lượng mưa năm so với giai } \\
\text { đoạn 1986-2005 (\%) }\end{array}$ & E.1.2 & + \\
\hline Bão, ATNĐ & $\begin{array}{l}\text { Số lượng cơn bão, áp thấp nhiệt đới, gây ảnh } \\
\text { hưởng trong } 10 \text { năm (cơn) }\end{array}$ & E.1.3 & + \\
\hline Hạn hán & $\begin{array}{l}\text { Chỉ số khô hạn và mức độ biến đổi trong } 20 \\
\text { năm }\end{array}$ & E.1.6 & + \\
\hline \multirow[t]{2}{*}{ Ngập lũ } & Phạm vi ngập lớn nhất (>0.1m) (ha) & E.1.7 & + \\
\hline & Độ sâu ngập lớn nhất (m) & E. 1.8 & + \\
\hline
\end{tabular}

\begin{tabular}{cccccc}
\hline Chỉ số & $\mathbf{0 - 0 , 2}$ & $\mathbf{0 , 2 - 0 , 4}$ & $\mathbf{0 , 4 - 0 , 6}$ & $\mathbf{0 , 6 - 0 , 8}$ & $\mathbf{0 , 8 - 1 , 0}$ \\
\hline E & Rất thấp & Thấp & Vừa & Cao & Rất cao \\
S & Rất thấp & Thấp & Vừa & Cao & Rất cao \\
I & Rất thấp & Thấp & Vừa & Cao & Rất cao \\
\hline
\end{tabular}

Bảng 2. Bộ chỉ thị nguy cơ hứng chịu thiên tai $(\mathrm{E})$ trên địa bàn tỉnh Bình Phước. 
Bảng 3. Bộ chỉ thị mức độ nhạy cảm với nguy cơ thiên tai $(\mathrm{S})$ trên địa bàn tỉnh Bình Phước.

\begin{tabular}{|c|c|c|c|}
\hline Khía cạnh (1) & Chỉ thị (2) & Ký hiệu & $\begin{array}{c}\text { Mối } \\
\text { quan hệ }\end{array}$ \\
\hline Tài nguyên & Diện tích rừng phòng hộ (ha) & S.1.1.1 & - \\
\hline \multirow[t]{2}{*}{ rừng } & Diện tích rừng đặc dụng (ha) & S.1.1.2 & - \\
\hline & Diện tích rừng sản xuất (ha) & S.1.1.3 & - \\
\hline \multirow[t]{4}{*}{ Sử dụng đất } & $\begin{array}{l}\text { Đất sản xuất nông nghiệp: Đất trồng cây hàng năm, đất trồng lúa, đất } \\
\text { cỏ dùng vào chăn nuôi, đất trồng cây hàng năm khác (ha) }\end{array}$ & S.1.2.1 & + \\
\hline & $\begin{array}{l}\text { Đất lâm nghiệp: có rừng (rừng sản xuất rừng phòng hộ, rừng đặc } \\
\text { dụng) (ha) }\end{array}$ & S.1.2.2 & - \\
\hline & $\begin{array}{l}\text { Đất chuyên dùng: Đất trụ sở cơ quan, công trình sự nghiệp, đất quốc } \\
\text { phòng - an ninh, đất sản xuất, kinh doanh phi nông nghiệp, đất có mục } \\
\text { đích công cộng (ha) }\end{array}$ & S.1.2.3 & + \\
\hline & Đất ở: Đất ở đô thị, đất ở nông thôn (ha) & S.1.2.4 & + \\
\hline $\begin{array}{l}\text { Tài nguyên } \\
\text { khoáng sản }\end{array}$ & Tổng diện tích khoáng sản theo từng huyện/thị (ha) & S.1.3.1 & - \\
\hline Tài nguyên & Nhu cầu sử dụng nước dưới đất (m³/ngày) & S.1.4.1 & - \\
\hline \multirow[t]{2}{*}{ nước } & Nhu cầu sử dụng nước sinh hoạt tại các vùng đô thị (m³/ngày) & S.1.4.2 & - \\
\hline & Nhu cầu sử dụng nước sinh hoạt tại các vùng nông thôn (m³/ngày) & S.1.4.3 & - \\
\hline
\end{tabular}

\subsection{Phương pháp nội suy không gian}

Phương pháp này được áp dụng để tính toán khả năng phơi nhiễm của các khu vực khác nhau trong phạm vi nghiên cứu. Phương nghịch đảo khoảng cách (Inverse Distance to a Power) và phần mềm Surfer 10.0 được sử dụng.

Phương pháp nghịch đảo khoảng cách xác định các giá trị cho các ô lưới bằng cách tính trung bình các giá trị của các điểm mẫu trong vùng lân cận của mỗi ô lưới. Điểm càng gần điểm trung tâm (đang xác định) càng có ảnh hưởng nhiều hơn.

Công thức nội suy:

Trong đó:

$$
\hat{Z}\left(S_{0}\right)=\sum_{i=1}^{n} \lambda_{i} Z\left(S_{i}\right)
$$

$$
\lambda_{i}=\frac{d_{i 0}^{-p}}{\sum_{i=1}^{n} d_{i 0}^{-p}}
$$

Trong đó $\mathrm{d}_{\mathrm{ij}}$ là khoảng cách không gian giữa 2 điểm thứ $\mathrm{i}$ và thứ $\mathrm{j}$, số mũ $\mathrm{p}$ càng cao, mức độ ảnh hưởng của các điểm ở xa càng thấp và một số xem như không đáng kể, thông thường $\mathrm{p}=2$. Tuy nhiên, trong một số trường hợp mật độ dữ liệu đầu vào cao, $\mathrm{p}$ phải tăng cao tương ứng. Trong đề tài này, dự kiến áp dụng $\mathrm{p}=5$.

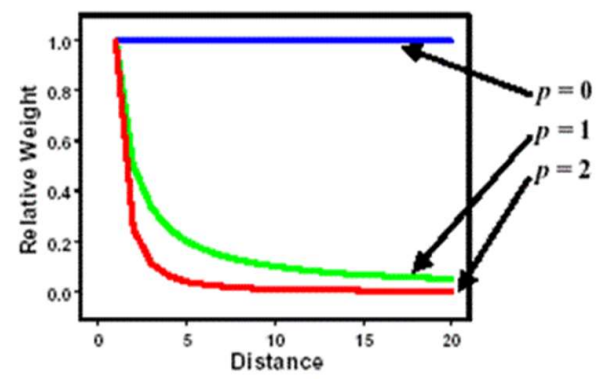

Hình 3. Mối quan hệ giữ sự ảnh hưởng và khoảng cách. 


\subsection{Phương pháp lập bản đồ}

Lớp bản đồ chỉ số tác động được tính toán từ đề tài nghiên cứu chồng lớp lên các lớp ranh giới hành chính, lớp dữ liệu khoáng sản.

Và các bản đồ chỉ số tác động được xây dựng bằng kỹ thuật tích hợp thông tin, chồng ghép các lớp thông tin có trọng số, tổng hợp, tính toán cho các chỉ số chính và chỉ số phụ... thông qua phần mềm ArcGIS 10.1 trên bản đồ nền tỷ lệ 1: 50.000, hệ tọa độ VN_2000.

\section{Kết quả và thảo luận}

Dựa trên bản đồ hiện trạng khoáng sản năm 2015 (khai thác khoáng sản) và bản đồ loại khoáng sản và công ty khai thác kết hợp với bộ chỉ số hứng chịu $(\mathrm{E})$ và bộ chỉ số nhạy cảm (S) trình bày ở mục 2.2 trong bảng 2 và bảng 3 . Từ đó, chúng tôi thực hiện tính toán mức độ nhạy cảm, hứng chịu cho tỉnh Bình Phước và tác động của $B Đ K H$ đến lĩnh vực khai thác khoáng sản khu vực tiềm năng khoáng sản sẽ bị ảnh hưởng lớn.

Bảng 4. Kết quả tính toán chỉ số tác động I đến lĩnh vực khoáng sản tỉnh Bình Phước.

\begin{tabular}{|c|c|c|c|c|c|c|c|c|c|c|c|c|}
\hline $\begin{array}{l}\text { Huyện } \\
\text { thành }\end{array}$ & $\begin{array}{l}\text { Chỉ } \\
\text { số E }\end{array}$ & $\begin{array}{l}\text { Chỉ } \\
\text { số } S\end{array}$ & $\begin{array}{c}\text { I KS } \\
45- \\
2025\end{array}$ & $\begin{array}{c}\text { I KS } \\
45- \\
2030\end{array}$ & $\begin{array}{c}\text { I KS } \\
45- \\
2050\end{array}$ & $\begin{array}{c}\text { I KS } \\
45- \\
2070\end{array}$ & $\begin{array}{c}\text { I KS } \\
45- \\
2100\end{array}$ & $\begin{array}{c}\text { I KS } \\
85- \\
2025\end{array}$ & $\begin{array}{c}\text { I KS } \\
85- \\
2030\end{array}$ & $\begin{array}{c}\text { I KS } \\
85- \\
2050\end{array}$ & $\begin{array}{c}\text { I KS } \\
85- \\
2070\end{array}$ & $\begin{array}{c}\text { I KS } \\
85- \\
2100\end{array}$ \\
\hline Đồng Xoài & 0,33 & 0,21 & 0,36 & 0,37 & 0,36 & 0,38 & 0,37 & 0,37 & 0,37 & 0,37 & 0,38 & 0,38 \\
\hline Phước Long & 0,37 & 0,24 & 0,45 & 0,48 & 0,47 & 0,49 & 0,49 & 0,43 & 0,44 & 0,49 & 0,49 & 0,49 \\
\hline Bình Long & 0,37 & 0,24 & 0,45 & 0,43 & 0,43 & 0,43 & 0,44 & 0,44 & 0,42 & 0,43 & 0,43 & 0,43 \\
\hline Chơn Thành & 0,35 & 0,25 & 0,45 & 0,45 & 0,44 & 0,44 & 0,45 & 0,45 & 0,45 & 0,44 & 0,44 & 0,44 \\
\hline Hớn Quản & 0,37 & 0,25 & 0,51 & 0,50 & 0,50 & 0,49 & 0,51 & 0,51 & 0,50 & 0,50 & 0,49 & 0,49 \\
\hline Đồng Phú & 0,32 & 0,26 & 0,44 & 0,47 & 0,45 & 0,46 & 0,46 & 0,45 & 0,48 & 0,46 & 0,46 & 0,47 \\
\hline Lộc Ninh & 0,38 & 0,19 & 0,48 & 0,47 & 0,47 & 0,46 & 0,48 & 0,46 & 0,46 & 0,47 & 0,46 & 0,46 \\
\hline Phú Riềng & 0,36 & 0,25 & 0,49 & 0,51 & 0,49 & 0,51 & 0,51 & 0,47 & 0,48 & 0,50 & 0,51 & 0,49 \\
\hline Bù Đăng & 0,36 & 0,21 & 0,47 & 0,47 & 0,46 & 0,48 & 0,47 & 0,47 & 0,46 & 0,48 & 0,48 & 0,48 \\
\hline Bù Đốp & 0,41 & 0,23 & 0,51 & 0,50 & 0,51 & 0,52 & 0,53 & 0,48 & 0,48 & 0,52 & 0,52 & 0,50 \\
\hline Bù Gia Mập & 0,43 & 0,17 & 0,60 & 0,60 & 0,59 & 0,59 & 0,60 & 0,55 & 0,56 & 0,60 & 0,59 & 0,58 \\
\hline
\end{tabular}

Kết quả chỉ số tác động (I) trong bảng 4 và hình 4 , hình 5 cho thấy, mức độ tác động do $\mathrm{BĐKH}$ đến tiềm năng khai thác khoáng sản là ở mức vừa và cao, cao nhất là 0,60 , dao động từ $0,36-0,60$, tức là ở thang thứ 3 (màu cam) và thứ 4 (màu đỏ) trong thang mức độ tác động.

- Các huyện, thành, thị như Đồng Xoài, Phước Long, Bình Long, Chơn Thành, Hớn Quản, Đồng Phú, Lộc Ninh, Phú Riềng, Bù Đăng hứng chịu trước BĐKH thấp, nhưng tiệm cận đến mức vừa (chỉ số $\mathrm{E}$ từ $0,32-0,38$ ), còn huyện Bù Đốp và Bù Gia Mập hứng chịu trước $\mathrm{BĐKH}$ vừa $(\mathrm{E}$ từ $0,41-0,43)$.

- Trong khi đó, tỉnh Bình Phước mức độ nhạy cảm với BĐKH là thấp, trong đó thấp nhất là huyện Lộc Ninh và Bù Gia Mập. Huyện Bù Gia Mập có tỷ lệ rừng cao nên mức nhạy cảm trung bình rất thấp nhưng nếu rừng suy giảm thì mức nhạy cảm cần xem xét lại. Các huyện thành còn lại có mức độ nhạy cảm ở thang thứ hai là thấp, từ $0,20-0,40$.

+ TP. Đồng Xoài chịu mức độ tác động thấp nhất ở tất cả kịch bản, mức độ tác động cũng ở mức thấp theo 5 thang đánh giá, giá trị $\mathrm{I}$ là $0,36-0,38$. Điều này cũng giải thích rằng vì mức độ hứng chịu (khoảng 0,33 ) và nhạy cảm (khoảng 0,21$)$ trước $\mathrm{BĐKH}$ của $\mathrm{TP}$. Đồng Xoài là thấp, bên cạnh đó thành phố có khả năng thích cao, đồng thời thành phố là trung tâm dịch vụ, giáo dục của tỉnh, không có nhiều các khu vực khai thác khoáng sản.

+ Bốn huyện gồm Bù Đốp, Bù Gia Mập, Hớn Quản và Phú Riềng chịu tác động do BĐKH cao nhất trong các huyện thị, ở mức cao trong thang thứ 3 (theo thang đánh giá), ở tất cả các kịch bản đều màu cam. Riêng huyện Bù Gia Mập lên đến mức đỏ là phải cẩn trọng 
nhất bởi mức tác động do $\mathrm{BĐKH,} \mathrm{khu} \mathrm{vực} \mathrm{khai} \mathrm{thác} \mathrm{khoáng} \mathrm{sản} \mathrm{phải} \mathrm{được} \mathrm{xem} \mathrm{xét} \mathrm{kỹ} \mathrm{lưỡng,}$ các loại đất cũng cần được kiểm tra do mưa lớn, hạn hán và ngập sẽ ảnh hưởng lớn $(0,36$ 0,43, chỉ số E).

+ Các huyện, thị còn lại có mức độ tác động do BĐKH đến tiềm năng khai thác khoáng sản cũng đáng quan tâm, vì dao động từ $0,42-0,51$. Những huyện thị này tập trung nhiều mỏ khai thác lớn, gần như tập trung ở các huyện như Bù Đăng, Lộc Ninh, Chơn Thành. Do vậy cần cẩn trọng và các biện pháp và quy hoạch đáng lưu ý.

Trước những tác động như vậy của $\mathrm{B} Đ K H$, các huyện thị cũng cần lưu ý biện pháp và khả năng thích ứng trước $\mathrm{BĐKH} \mathrm{để} \mathrm{làm} \mathrm{giảm} \mathrm{mức} \mathrm{hứng} \mathrm{chịu} \mathrm{xuống,} \mathrm{trong} \mathrm{đó} \mathrm{phải} \mathrm{lồng} \mathrm{ghép} \mathrm{đến}$ lĩnh vực khoáng sản. Những khu vực tiềm năng khoáng sản như huyện Hớn Quản và Phú Riềng cần đặc biệt cẩn trọng do hai huyện này chịu tác động vừa nhưng mức độ tổn thương cũng cao. Khi quy hoạch khai thác khoáng sản cần lưu tâm đến huyện Bù Đốp và Bù Gia Mập đây là hai huyện có mức hứng chịu $\mathrm{BĐKH} \mathrm{lớn,} \mathrm{tác} \mathrm{động} \mathrm{cao,} \mathrm{tổn} \mathrm{thương} \mathrm{cao.}$

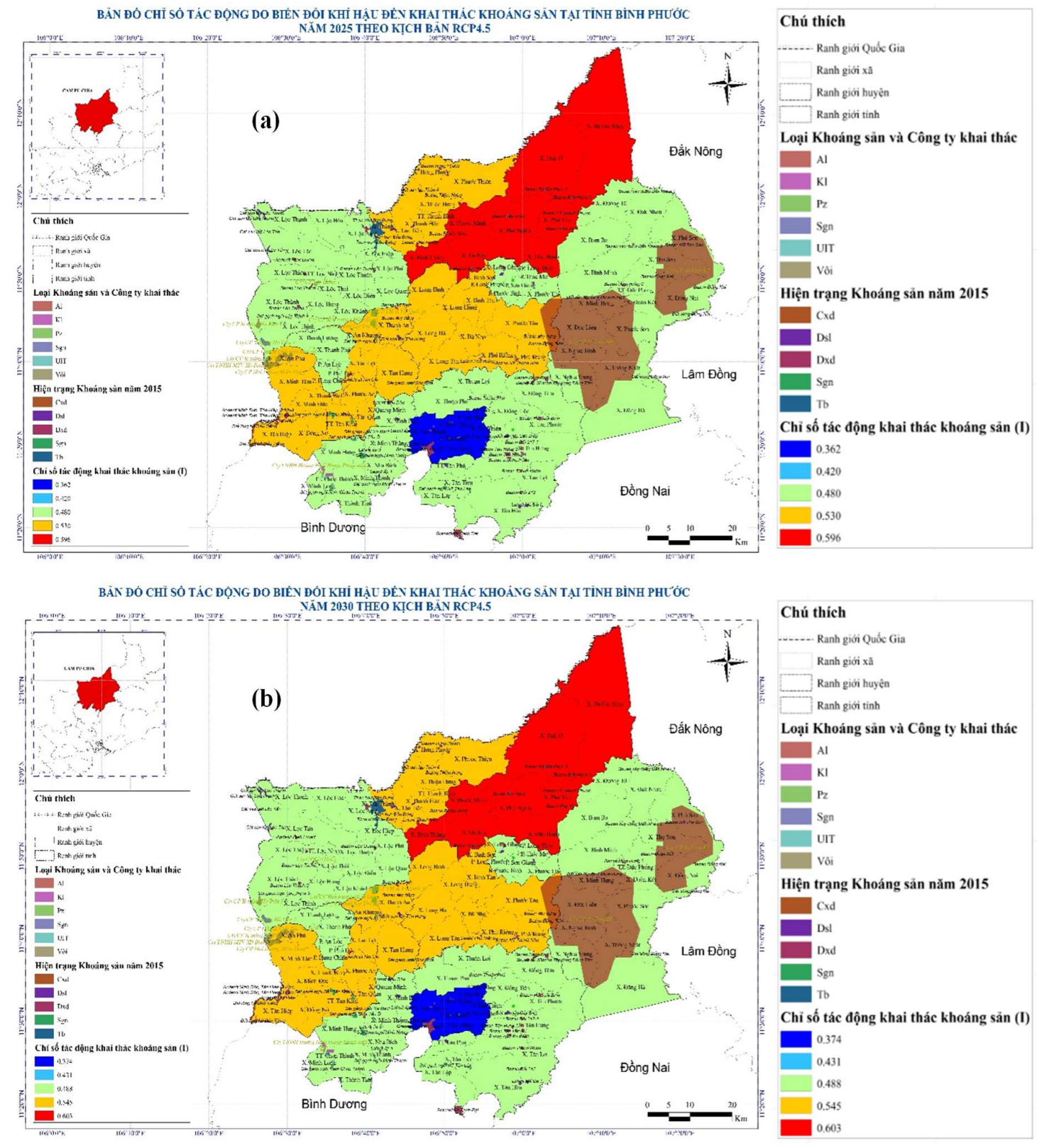




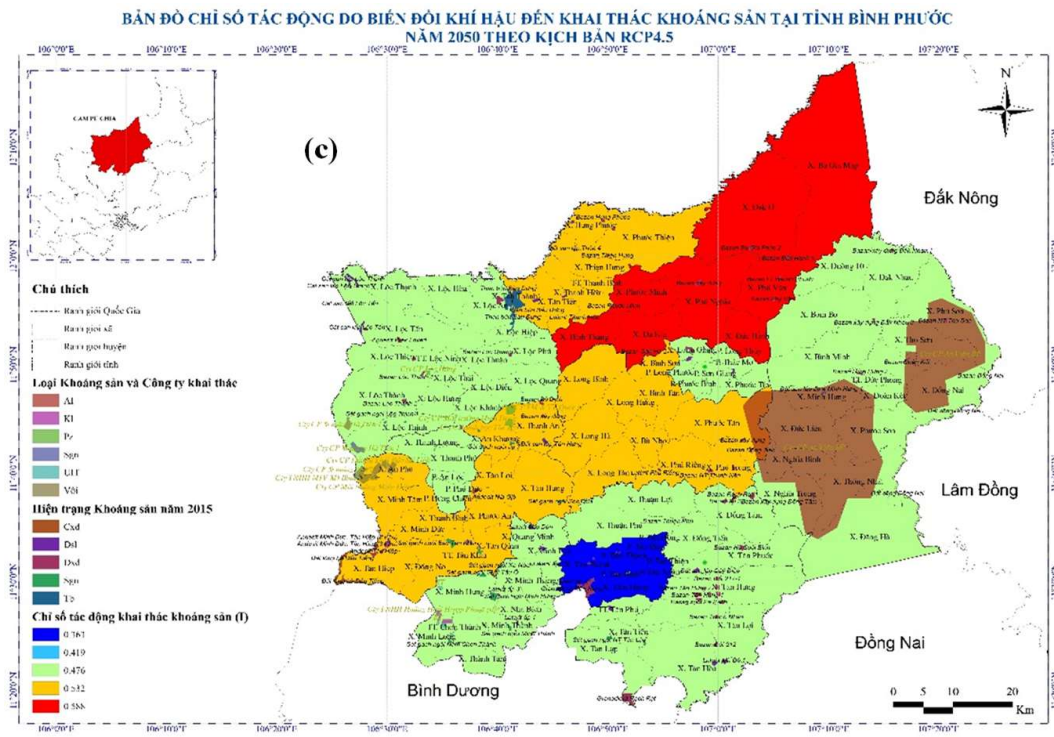

Chú thích

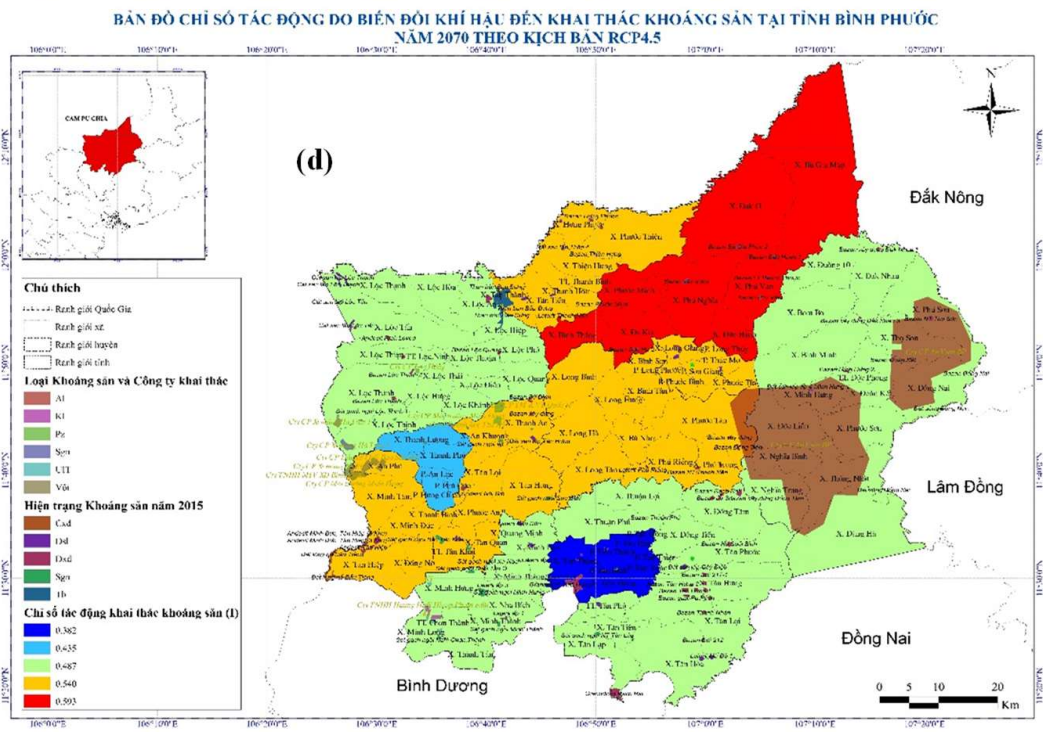

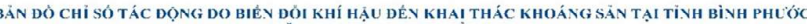

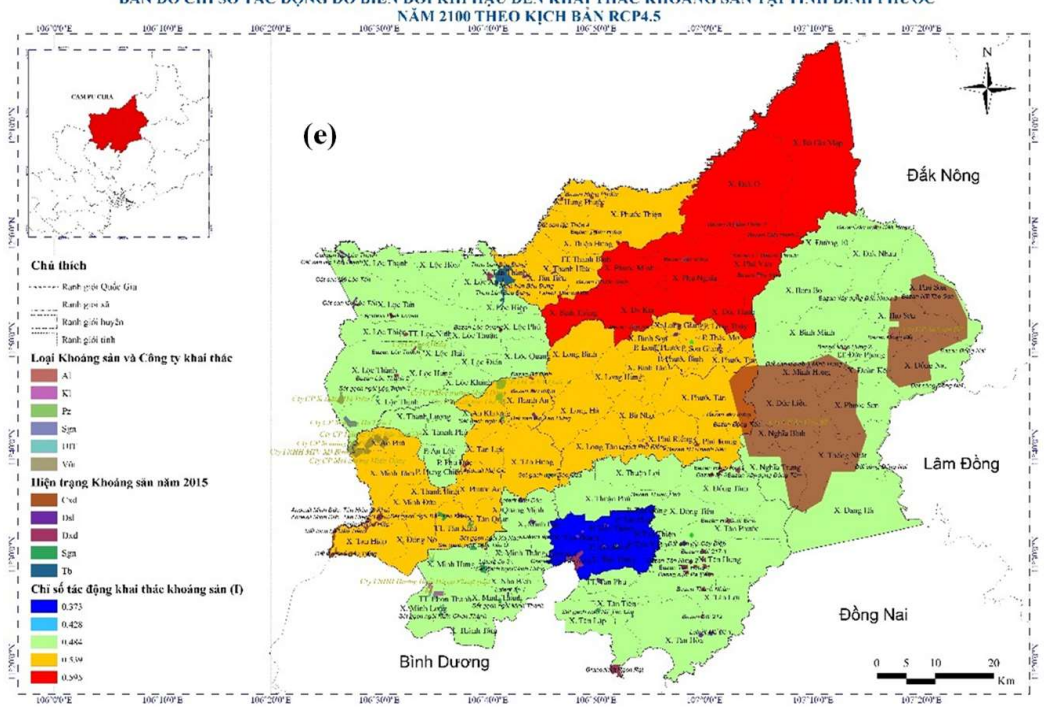

\begin{tabular}{|c|c|}
\hline Non & 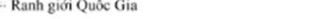 \\
\hline & Ranh giói xă \\
\hline & Ranh giới huyên \\
\hline & Ranh giới tình \\
\hline Loại 1 & Khoáng sản và Công ty khai thác \\
\hline & Al \\
\hline & $\mathrm{KI}$ \\
\hline & $\mathrm{Pz}$ \\
\hline & Sgn \\
\hline & UIT \\
\hline & Vối \\
\hline Hiện & trạng Khoáng sản năm 2015 \\
\hline & Cxd \\
\hline & DsI \\
\hline & Dxd \\
\hline & Sgn \\
\hline & $\mathrm{Tb}$ \\
\hline Chì sét & số tác động khai thác khoáng sản (I) \\
\hline & 0.363 \\
\hline & 0.419 \\
\hline & 0.476 \\
\hline & 0.532 \\
\hline & 0.588 \\
\hline
\end{tabular}

Chú thích

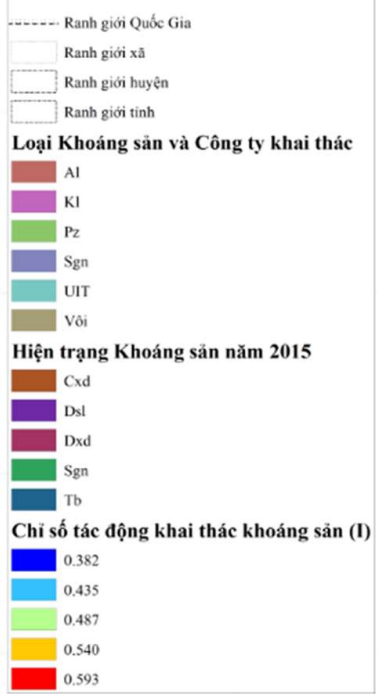

Chú thích

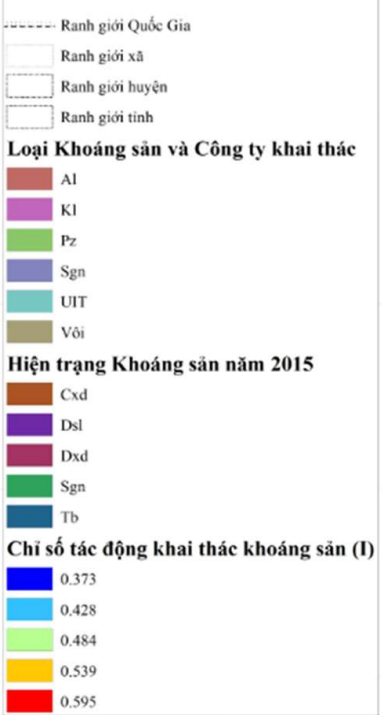

Hình 4. Bản đồ chỉ số tác động do BĐKH tỉnh Bình Phước theo kịch bản RCP4.5. 
Theo từng kịch bản BĐKH, mức độ tác động đến khu vực tiềm năng khai thác khoáng sản. Vào năm 2025, chỉ số $\mathrm{I}$ ở mức từ $0,37-0,55$. Tuy nhiên các khu vực có chịu tác động cao là ở các huyện Bù Gia Mập, Hớn Quản, kế đến là Bù Đốp, Bù Đăng và Phú Riềng.

Đến năm 2030, chỉ sô $I$ ở mức từ vừa, tăng hơn một chút so với năm 2025 ở kịch bản RCP 4.5. Tuy nhiên các khu vực khai thác khoáng sản bị tác động cao đã thay đổi, Đồng Phú ở giữa thế kỷ chịu mức tác động vừa. Vào năm 2050 , chỉ số $\mathrm{I}$ cao nhất tới 0,60 , dao dộng trong khoảng từ $0,37-0,60$. Trong đó có $4 / 11$ huyện thị ở mức vừa là Bù Gia Mập, Bù Đốp, Phú Riềng, Hớn Quản. Khu vực không thay đổi nhiều so với năm 2025 và 2030 nhưng mức tác động cao hơn. Đến cuối thế kỷ, phạm vi tác động rộng không thay đổi, và mức độ tác động cao từ $0.36-0,59$. Và $4 / 11$ huyện thị xuyên suốt luôn bị mức tổn thương cao là Bù Gia Mập, Bù Đốp, Phú Riềng, Hớn Quản. TP. Đồng Xoài vẫn là thành phố chịu mức độ tổn thương thấp nhất từ $0,35-0,38$, ở kịch bản này TX. Bình Long có mức tác động giảm xuống so với các tỉnh khác.

Nguyên nhân dẫn đến mức độ tác động của BĐKH đến khoáng sản cao là do phơi nhiễm của tỉnh có nguy cơ tăng cao chủ yếu do các hiện tượng thời tiết cực đoan (mưa, bão, nhiệt, ngập, hạn hán, ...) ngày càng có xu hướng gia tăng do BĐKH. Bên cạnh đó, tính nhạy cảm của địa phương cũng khá cao, xuất phát từ các loại tài nguyên thiên nhiên cũng như lĩnh vực kinh tế còn phụ thuộc vào thời tiết, sức ép gia tăng dân số. Biểu hiện rõ nét nhất đó là huyện Bù Gia Mập và Lộc Ninh dù mức độ nhạy cảm trung bình của kinh tế xã hội với $\mathrm{BĐKH} \mathrm{ở}$ thang rất thấp nhưng mức độ hứng chịu trung bình của kinh tế xã hội cao, dần đến tác động cao, còn TP. Đồng Xoài thì ngược lại. Những khu vực tiềm năng khai thác khoáng sản là Phú Riềng, Hớn Quản, Bù Đăng cần đáng lưu tâm nhất, nơi đây tập trung các mỏ Laterit, sét gạch ngói, cát, Andesit, đất san lấp và nhiều công ty khai thác khoáng sản tập trung ở đây.

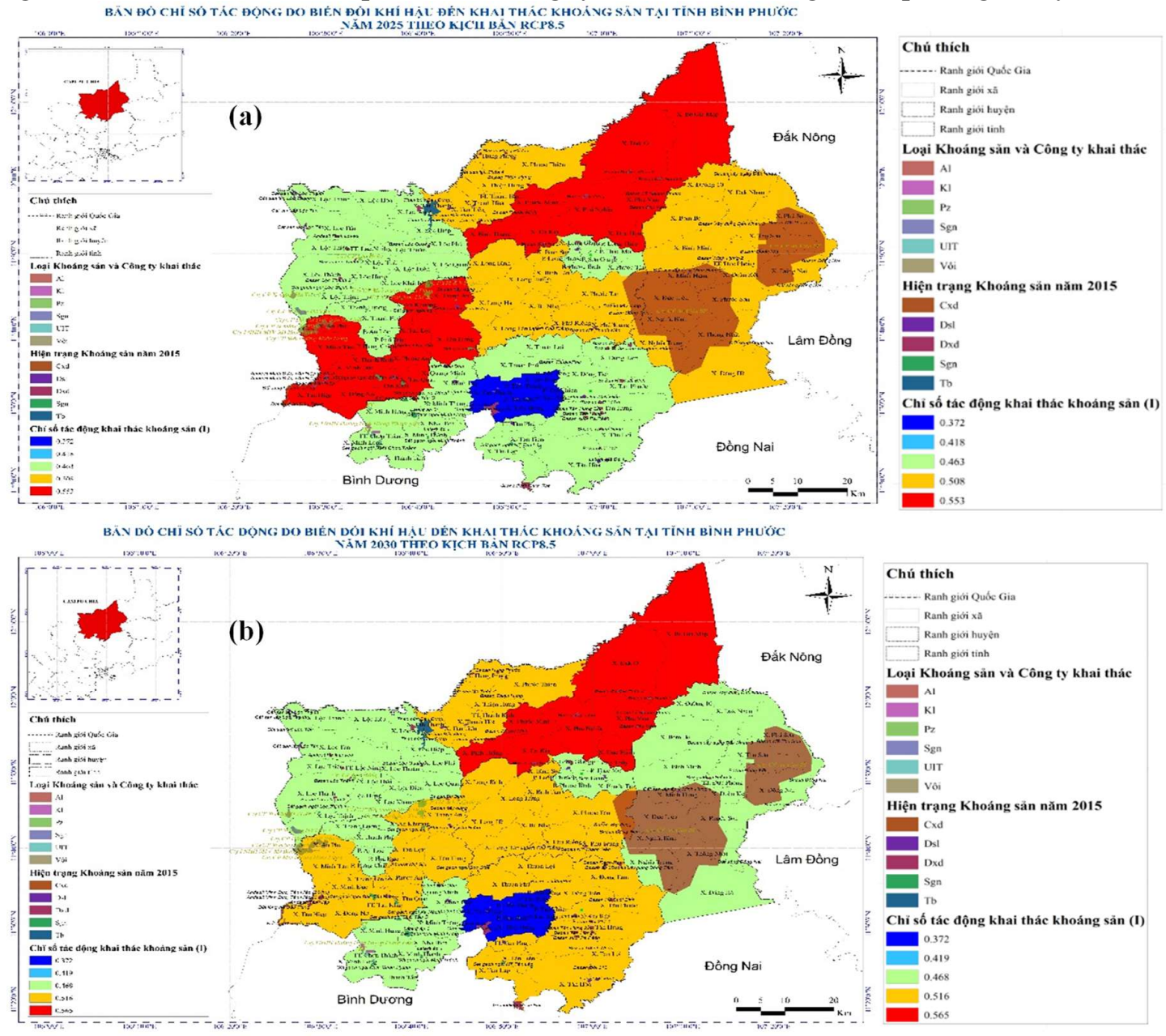



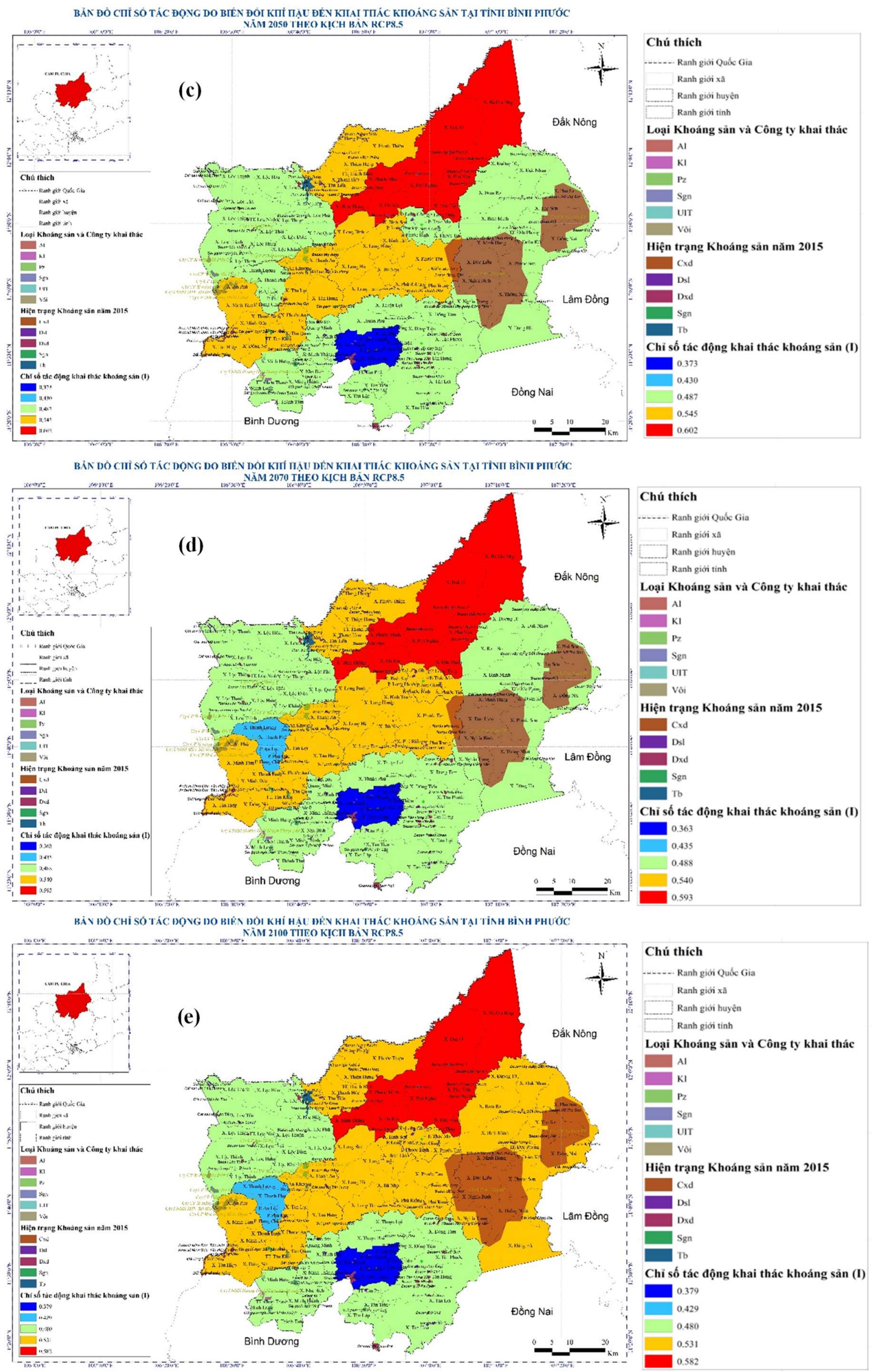

Hình 5. Bản đồ chỉ số tác động do BĐKH tỉnh Bình Phước theo kịch bản RCP8.5. 


\section{Kết luận}

Bài báo đã đánh giá mức độ tác động của $\mathrm{BĐKH} \mathrm{đến} \mathrm{tiềm} \mathrm{năng} \mathrm{khai} \mathrm{thác} \mathrm{khoáng} \mathrm{sản}$ tỉnh Bình Phước. Qua quá trình phân tích, đánh giá mức độ tổn thương đến tiềm năng kinh tế xã hội dựa trên mức độ nhạy cảm, khả năng hứng chịu và khả năng thích ứng có thể nhận thấy rằng:

- Các huyện, thành, thị như: Đồng Xoài, Phước Long, Bình Long, Chơn Thành, Hớn Quản, Đồng Phú, Lộc Ninh, Phú Riềng, Bù Đăng hứng chịu trước BĐKH thấp (chỉ số E trung bình từ $0,32-0,38)$, còn huyện Bù Đốp và Bù Gia Mập hứng chịu trước $\mathrm{BĐKH}$ vừa $(\mathrm{E}$ trung bình từ $0,41-0,43$ ). Trong khi đó, tiềm năng kinh tế xã hội có mức nhạy cảm với BĐKH thấp, trong đó thấp nhất là huyện Lộc Ninh và Bù Gia Mập, các huyện thành còn lại có mức độ nhạy cảm thấp. Tuy nhiên vì mức độ hứng chịu trước thiên tai của huyện Lộc Ninh và Bù Gia Mập là mức vừa, kết hợp khả năng thích ứng tương đối thấp do vậy mức độ tổn thương là cao trên 0,70 .

- Bốn huyện gồm Bù Đốp, Bù Gia Mập, Hớn Quản và Phú Riềng chịu tác động do BĐKH đến tiềm năng khai thác khoáng sản cao nhất trong các huyện thị, ở mức cao trong thang thứ 3 (theo thang đánh giá), ở tất cả các kịch bản đều màu cam. Riêng huyện Bù Gia Mập lên đến mức đỏ là phải cẩn trọng nhất bởi mức tác động do $\mathrm{B} Đ K H$, khu vực khai thác khoáng sản phải được xem xét kỹ lưỡng, các loại đất cũng cần được kiểm tra do mưa lớn, hạn hán và ngập sẽ ảnh hưởng lớn. Do vậy các huyện này phải phải đánh giá lại tiềm năng có nên khai thác thêm hay không, và khi khai thác cần cận trọng trong đánh giá khai thác tài nguyên trong tương lai. Chính vì thế, khai thác quá mức đặc biệt là rừng, bazan: những loại nhạy cảm do mưa, ngập sẽ khiến mức độ nhạy cảm tăng và như vậy sự tác động là rất lớn, ngoài ra huyện Phú Riềng và huyện Hớn Quản tập trung nhiều công ty, mỏ khai thác khoáng sản nên đặc biệt phải lưu tâm sự tác động.

- Các huyện, thị còn lại của tỉnh Bình Phước có mức độ tác động do BĐKH đến tiềm năng khai thác khoáng sản cũng đáng quan tâm, vì dao động từ $0,42-0,51$. Những huyện thị này tập trung nhiều mỏ khai thác lớn, gần như tập trung ở các huyện như Bù Đăng, Lộc Ninh, Chơn Thành. Do vậy cần cẩn trọng và các biện pháp và quy hoạch đáng lưu ý.

- Đến cuối thể kỷ, phạm vi tác động rộng không thay đổi, và mức độ tác động cao từ 0,36-0,59. Trong đó, 4/11 huyện thị luôn bị mức tổn thương cao là Bù Gia Mập, Bù Đốp, Phú Riềng, Hớn Quản. TP. Đồng Xoài vẫn là thành phố chịu mức độ tổn thương thấp nhất từ $0,35-0,38$, ở kịch bản này TX. Bình Long có mức tác động giảm xuống so với các huyện khác.

Những khu vực tiềm năng khai thác khoáng sản là Phú Riềng, Hớn Quản, Bù Đăng cần đáng lưu tâm nhất, nơi đây tập trung các mỏ Laterit, sét gạch ngói, cát, Andesit, đất san lấp và nhiều công ty khai thác khoáng sản tập trung ở đây. Nhưng những tài nguyên khoáng sản, các mỏ khai thác dễ bị tổn thương với các yếu tố BĐKH. Nhiệt độ cao, khô hạn sẽ làm nghiêm trọng hơn các vụ cháy rừng trên địa bàn tỉnh, các trận mưa lớn, ngập dễ phá hủy các các loại khoáng sản, nguy hiểm cho các mỏ đang khai thác.

Đóng góp của tác giả: Xây dựng ý tưởng nghiên cứu: L.H.N., P.T.L.; Lựa chọn phương pháp nghiên cứu: L.H.N., P.T.L., T.T.H.; Xử lý số liệu: N.V.T., H.C.T.; Tính toán: N.V.T., H.C.T.; Phân tích kết quả: L.H.N., N.V.T., H.C.T.; Viết bản thảo bài báo: L.H.N., N.V.T., H.C.T.; Chỉnh sửa bài báo: H.C.T.

Lời cảm ơn: Nghiên cứu này được thực hiện dưới sự tài trợ của đề tài nghiên cứu khoa học cấp Tỉnh là đề tài: "Đánh giá ảnh hưởng của $\mathrm{BĐKH} \mathrm{đến} \mathrm{biến} \mathrm{động} \mathrm{diện} \mathrm{tích} \mathrm{và} \mathrm{cơ} \mathrm{cấu} \mathrm{sử}$ dụng đất, tiềm năng phát triển kinh tế xã hội, tiềm năng khai thác các loại tài nguyên khoáng sản trên địa bàn tỉnh Bình Phước". 
Lời cam đoan: Tập thể tác giả cam đoan bài báo này là công trình nghiên cứu của tập thể tác giả, chưa được công bố ở đâu, không được sao chép từ những nghiên cứu trước đây; không có sự tranh chấp lợi ích trong nhóm tác giả.

\section{Tài liệu tham khảo}

1. Viện Khoa học Khí tượng Thủy văn và Môi trường. Hướng dẫn Đánh giá tác động của biến đổi khí hậu và xác định các giải pháp thích ứng. NXB Tài nguyên-Môi trường và Bản đồ Việt Nam, 2011.

2. IPCC. Climate Change 2007: Impacts, Adaptation and Vulnerability. Contribution of Working Group II to the Fourth Assessment Report of the Intergovernmental Panel on Climate Change. Parry, M.L.; Canziani, O.F.; Palutikof, J.P.; van der Linden, P.J.; Hanson, C.E. (Eds.) Cambridge University Press, Cambridge, UK, 2007, pp. 976.

3. Bộ Tài nguyên và Môi trường. Kịch bản biến đổi khí hậu và nước biển dâng cho Việt Nam, 2012.

4. Bộ Tài nguyên và Môi trường. Kịch bản biến đổi khí hậu và nước biển dâng cho Việt Nam, 2016.

5. Hoàng, T.T. Đánh giá hiện trạng ngập lụt và xác định kịch bản biến đổi khí hậu và nước biển dâng cho TP. Hồ Chí Minh. Dự án: Việt Nam xây dựng Thông báo Quốc Gia lần thứ ba cho Công ước khí hậu, 2017.

6. Long, P.T. Xây dựng kịch bản biến đồi khí hậu và dự báo xâm nhập mặn theocác kịch bản biến đổi khí hậu cho khu vực Đồng bằng sông Cửu Long. Dự án: Việt Nam xây dựng Thông báo Quốc Gia lần thứ ba cho Công ước khí hậu, 2017.

7. Thủy, T.T.T.; Thăng, V.V.; Quyền, N.H.; Hiệu, N.T.; Hiền, T.D.; Thanh, L.H. Xây dựng bản đồ phân bố cấp độ tác động của biến đổi khí hậu đến quy hoạch, thăm dò, khai thác, chế biến và sử dụng các khoáng sản chủ yếu ở Việt Nam. Tạp chí Khi tượng Thüy văn 2020, 720, 23-31.

8. Khắc, H.N.; Hải, T.T.T. Tác động của nước biển dâng do biến đổi khí hậu đến vùng nuôi trồng thủy sản khu vực ven biển Bắc Bộ và Bắc Trung Bộ. Tạp chí Khí tuợng Thủy văn 2020, 715, 68-77. https://doi.org/10.36335/VNJHM.2020(715).68-77.

9. Khiêm, M.V. Đánh giá tác động của biến đổi khí hậu đến ngập lụt tại TP. Hồ Chí Minh và đề xuất các biện pháp thích ứng với biến đổi khí hậu. Dự án: Việt Nam xây dựng Thông báo Quốc Gia lần thứ ba cho Công ước khí hậu, 2017.

10. Phùng, N.K.; Tâm, L.V. Đánh giá tác động của biến đổi khí hậu đến tự nhiên, con người và kinh tế-xã hội thành phố Hồ Chí Minh, 2011.

11. Bộ Tài nguyên và Môi trường. Thông báo Quốc Gia lần thứ hai cho Công ước khung của Liên Hợp Quốc về biến đổi khí hậu, 2010.

12. Bộ Tài nguyên và Môi trường. Thông báo Quốc Gia lần thứ ba cho Công ước khung của Liên Hợp Quốc về biến đồi khí hậu, 2018.

13. Cổng thông tin điện tử Tỉnh Bình Phước: https://binhphuoc.gov.vn/.

14. Allison, P.D. Fixed Effects Regression Models. Library in the United States of America. SAGE Publications Asia-Pacific Pte. Ltd, 2009.

15. Thục, T.; Tường, L.N.; Thắng, N.V.; Thái, T.H. Thích ứng với biến đổi khí hậu và phát triển bền vững. Báo cáo hội thảo Tham vấn quốc gia về chương trình mục tiêu quốc gia ứng phó với biến đổi khí hậu và nước biển dâng, 2008, 4-12.

16. Thục, T.; Hương, T.T.T.; Thắng, N.V.; Nhuận, M.T.; Trí, L.Q.; Thành, L.Đ.; Hương, H.T.L.; Sơn, V.T.; Thuận, N.T.H. và Tường, L.N. Báo cáo đặc biệt của Việt Nam về Quản lý rủi ro thiên tai và hiện tượng cực đoan nhằm thúc đẩy thích ứng với biến đổi khí hậu. NXB Tài nguyên-Môi trường và Bản đồ Việt Nam, Hà Nội, Việt Nam, 2015.

17. Nam, L.H.; Tín, N.V.; Toàn, H.C.; Hoàng, T.T.; Long, P.T. Đánh giá xu thế và xây dựng kịch bản biến đổi khí hậu cho tỉnh Bình Phước. Tạp chí Khí tượng Thủy văn 2020, 717, 32-43. https://doi.org/10.36335/VNJHM.2020(717).32-43. 
18. Thắng, N.V.; Hiệu, N.T.; Thục, T. Biến đổi khí hậu và tác động ở Việt Nam. NXB Khoa học Công nghệ, Hà Nội, 2011.

19. Thủy, T.T.; Thục, T.; Hương, H.T.L. Đánh giá tính dễ bị tổn thương đối với đa thiên tai ở ven biển Trung Trung Bộ. Tạp chí Khi tiọng Thủy văn 2020, 718, 72-84. http://doi.org/10.36335/VNJHM.2020(718).72-84.

\title{
Assess the impact of climate change on the mineral exploitation potential of Binh Phuoc Province
}

\author{
Le Hoai Nam¹, Ho Cong Toan², Pham Thanh Long² \\ ${ }^{1}$ Southern Center for Enviromental Monitoring; lhnammt@gmail.com; \\ ${ }^{2}$ Sub-Institute of Hydrometeogology and Climate change; hocongtoanhdh@gmail.com; \\ longpham.sihymete@gmail.com
}

\begin{abstract}
The study provides analysis and assessment results of climate change (CC) impacts on mineral exploitation potentials in Binh Phuoc Province. To perform the study evaluation inherited the results of constructing the scenarios of temperature, rainfall, drought and inundation under the scenario of CC and sea level rise (SLR) in 2016 of the Ministry of Natural Resources and Environment and the set of indicators. The assessment is developed according to the guidance of the Intergovernmental Panel on Climate Change (IPCC) in 2007. On that basis, the results on the level of impacts and effects of CC on the mineral exploitation area in the province. Binh Phuoc is assessed to each district and region, specifically: the mining areas in Dong Xoai city (Dong Xoai city) suffer the lowest impact from 0.36-0.38; Bu Gia Map district has a high level of impacts from climate change on the mining area, with an impact index of about 0.60 . The remaining provinces of Binh Phuoc province have mining potentials that are affected moderately with the impact index of $0.43-$ 0.53 under the influence of CC. Although the article only shows the extent of the impact of $\mathrm{CC}$, not to mention other indicators, the research results have contributed to providing information for Binh Phuoc Province, serving the planning of areas exploiting the worms. in the context of CC.
\end{abstract}

Keywords: Impact of Climate change; Mineral. 